\title{
CAMBIOS DE USOS DE SUELO EN PASO DE LOS LIBRES, CORRIENTES, ARGENTINA ENTRE 1990 Y 2016. Impacto del Proceso de Expansión Urbana \\ CHANGES IN LAND USE IN PASO DE LOS LIBRES, CORRIENTES, ARGENTINA BETWEEN 1990 AND 2016. Impact of the urban expansion process.
}

Agrim. Prof. Laura Fabiana Gomez.

Departamento de Agrimensura - Facultad de Ciencias Exactas y Naturales y Agrimensura (FaCENA) Universidad Nacional del Nordeste (UNNE)

\section{RESUMEN}

El presente trabajo presenta un análisis de los cambios de usos de suelo ocurrido entre los años 1990 y 2016 en la ciudad de Paso de los Libres, Provincia de Corrientes, haciendo especial énfasis sobre aquellosresultantes de la expansión urbana de la ciudad. Se utilizaron imágenes del satélite Landsat 5 -sensor TM- y Landsat 8 -sensor OLI- para cada uno de los momentos citados, Sistemas de Información Geográfica (SIG) y se realizó el análisis de una matriz de tabulación cruzada para detectar información más específica de los cambios ocurridos en el territorio, con el fin de generar evidencia, información y conocimiento sobre las características de la expansión urbana de la ciudad.Las imágenes se clasificaron en cinco categorías: área urbana consolidada, área periurbana, infraestructura, cuerpos y cursos de agua, áreas verdes y cobertura vegetal urbana.

Los resultados muestran las particularidades de la expansión urbana reciente, el creciente consumo de suelo urbano, los cambios y la variabilidad en el uso del suelo y la consolidación de una ciudad de bajas densidades.

\section{PALABRAS CLAVES}

Expansión Urbana; Cambios de uso de Suelo; Paso de los Libres

\section{ABSTRACT}

This paper presents a study of changes in land use occurred between 1990 and 2016 in the city of Paso de los Libres, Province of Corrientes, with special emphasis on those resulting from the urban expansion of the city. Images from the Landsat 5 satellite -sensor TM- and Landsat 8 -sensor OLIwere used for each of the moments mentioned, Geographic Information Systems (GIS) and the analysis of a cross-tabulation matrix was carried out to detect more specific information of the changes occurred in the territory, in order to generate evidence, information and knowledge about the characteristics of the urban expansion of the city. The images were classified into five categories: consolidated urban area, peri-urban area, infrastructure, bodies and water courses, green areas and urban vegetation cover.

The results show the particularities of recent urban expansion, the increasing consumption of urban land, changes and variability in land use and the consolidation of a city with low densities.

\section{KEY WORDS}

Urban expansion; Changes in land use; Paso de los Libres 
Revista Geográfica Digital. IGUNNE. Facultad de Humanidades. UNNE. Año 15. № 30. Julio - Diciembre 2018. ISSN 1668-5180 Resistencia, Chaco

\section{INTRODUCCIÓN}

La ciudad es el hogar de la mayoría de los habitantes del planeta y su crecimiento es inevitable conforme crezca su población.Actualmente, el porcentaje de población mundial asciende al $55 \%$ y se estima que para el año 2050 dicho porcentaje alcanzará el 68\% (Naciones Unidas, 2018).

En este proceso de urbanización que no cesa es innegable el papel fundamental que juegan las ciudades de gran tamaño en el sistema de ciudades como concentradoras de recursos y actividades económicas, espacio donde se toman decisiones yse obtienen los mayores beneficios;sin embargo es en las ciudades de tamaño intermedio donde reside la mayor parte de la población. En el inicio del siglo XXI se estimaba que en el planeta, del total de residentes urbanos, el $13,8 \%$ se concentraba en ciudades de más de cinco millones de habitantes y el $62,5 \%$ en ciudades con menos de un millón de habitantes, éstas últimas urbes son denominadas intermedias ${ }^{1}$ (Bellet et al, 2004).Según López Trigalla tendencia actual es a un mayor protagonismo de las ciudades medias(López Trigal, 2010:118), éstas concentran la mayoría de la población urbana del planeta y por sus características y sus potencialidades son las que pueden ofrecer una fórmula válida para lograr la configuración de un sistema urbano equilibrado y sostenible (Ciudades Intermedias y Urbanización Mundial, 1999:19). En el año 2015, el número de ciudades con más de 1 millón de habitantes ascendía a 501 mientras que las ciudades intermedias eran $8.926^{2}$.

En Argentina, las ciudades intermedias concentran el $46 \%$ de la población, dato que revela la importancia que tienen en la estructuración del territorio (Tella et. al, 2018).

"Entre las características más sobresalientes del sistema urbano nacional, se advierte que se trata de un sistema centralizado y radio-concéntrico; subsistemas regionales poco relacionados entre sí y aún sin consolidar a lo que se suma la discontinuidad entre las jerarquías de los centros urbanos. Esta situación se originó, entre otras cuestiones, en las mejores condiciones laborales y de servicios que ofrecen los grandes centros urbanos, cuya población aumentó por el aporte de migrantes provenientes del interior de las provincias argentinas. Sin embargo y pese a ese crecimiento poblacional de las grandes ciudades, la mayoría de la población reside en ciudades intermedias o de menor tamaño" (Ramírez et al., 2015: 195). Como señalamos el concepto de "ciudad intermedia" depende del contexto territorial y de la función o rol que cumplen los centros en los sistemas urbanos jurisdiccionales, por lo tanto es importante analizar el papel que juega en la prestación de bienes y servicios y la función de nodo organizador del área donde se emplaza.

Como se ha dicho, el crecimiento de la población implica el crecimiento de la ciudad "pero la forma en que este ocurre puede hacer grandes diferencias en el tipo de urbe que resulte, con fuertes implicancias en términos de eficiencia, costos de transporte, calidad del espacio público y, en resumidas cuentas, calidad de vida para sus habitantes" (Hurtubia, R.et al. 2017)(http://www.plataformaurbana.cl/archive/2017/05/29/expansion-urbana-y-accesibilidad/). Como consecuencias negativas de la ausencia de planificación en el crecimiento urbano se encuentran el avance de las ciudades poco densas, desordenadas, discontinuas y poco consolidadas, gran cantidad de vacíos urbanos, asentamientos marginales en áreas vulnerables, contaminación y deterioro del ambiente, falta de equipamiento e infraestructura, entre otras. Estas externalidades no deseadas se pueden ejemplificar en el avance del modelo de ciudad difusa, este tipo de urbe se ve favorecida por la dominancia del transporte basado en el uso del vehículo privado, es así que se "plantean problemas ambientales negativos para un modelo de baja sostenibilidad (gastos energéticos mayores y destrucción o alteración del paisaje), problemas socio-económicos (mayores costes y dificultades en reparto de financiación de equipamientos, costes en la centralidad), problemas político-sociales (amenaza sobre los espacios públicos, nuevas desigualdades urbanas, nuevas escalas de segregación y aparición de ciudades cerradas y formación de guetos)" (López Trigal, 2010:101-102). En oposición, otros autores han abonado acerca de las bondades de la ciudad difusa como por ejemplo la calidad del entorno, un menor costo económico del suelo, así como razones dimensionales o funcionales de difícil ubicación en zonas urbanas persistentes como son

Publicado en formato digital: Agrim. Prof. Laura Fabiana Gomez. CAMBIOS DE USOS DE SUELO EN PASO DE LOS LIBRES, CORRIENTES, ARGENTINA ENTRE 1990 Y 2016. Impacto del Proceso de Expansión Urbana. Revista Geográfica Digital. IGUNNE. Facultad de Humanidades. UNNE. Año 15. № 30. Julio - Diciembre 2018. ISSN 1668-5180 Resistencia, Chaco.

En: http://hum.unne.edu.ar/revistas/geoweb/default.htm 
Revista Geográfica Digital. IGUNNE. Facultad de Humanidades. UNNE. Año 15. № 30. Julio - Diciembre 2018. ISSN 1668-5180 Resistencia, Chaco

instalaciones deportivas, comerciales o recreativas (Esteban, J., 2006 cit. en Mayor Farguell, X. 2007).

Lo que queda claro es que el crecimiento urbano, es un proceso que, dado su dinamismo, se debe seguir revisando, indagando y estudiando ya que es preciso avanzar hacia modelos sostenibles que procuren alcanzar el equilibrio apropiado y recoger las ventajas de los modelos de ciudad ya existentes.

Por lo expuesto, el interés de este trabajo se centra en la generación de información territorial derivada del análisis de la expansión y los cambios en el uso del suelo urbano en la ciudad de Paso de los Libres (Provincia de Corrientes), una de las ciudades intermedias del sistema urbano correntino, con el propósito de proveer conocimiento para la toma de decisiones de los actores involucrados en la planificación urbana. El análisis se centrará en los años 1990 y 2016 para mostrar los cambios más relevantes en los principales usos de suelo urbano cuyas categorías se expondrán más adelante. Se utilizarán imágenes del satélite Landsat, de acceso libre y gratuito, y el trabajo se apoyará en las funcionalidades que ofrecen las aplicaciones o recursos que permiten analizar los procesos derivados de la teledetección con fuerte utilización de los Sistemas de Información Geográfica (SIG).

De lo expuesto se desprenden los objetivos de la presente contribución: a) cuantificar el crecimiento de la población y la expansión del suelo urbano en Paso de los Libres (provincia de Corrientes, Argentina) entre 1990 y 2016; b) identificar los cambios en el uso del suelo urbano discriminando las categorías: área urbana consolidada (AUC), área periurbana (AP), infraestructura (INF), cuerpos y cursos de agua (CCA), áreas verdes y cobertura vegetal urbana (AVCVU); c) caracterizar las cubiertas según persistencia, ganancias, pérdidas, cambio neto y cambio total del suelo en cada una de ellas $y, d$ ) detectar las cubiertas que presentan mayor variabilidad en el lapso considerado con énfasis en la expansión del AUC.

\section{AREA DE ESTUDIO}

La provincia de Corrientes se localiza en la región nordeste de la República Argentina (mapa 1) se halla delimitada por los ríos Paraná, al norte y oeste -que la separa del vecino país de Paraguay y de las provincias del Chaco y Santa Fe, respectivamente- y Uruguay, al este -que la separa de los países Brasil y Uruguay-. Los arroyos Itaembé y Chimiray al noreste, la separan de la provincia de Misiones y los arroyos Guayquiraró y Mocoretá al sur, la separan de la provincia de Entre Ríos.

La ciudad de Paso de los libres se encuentra en la región denominada Centro-Sur de la provincia en el margen izquierdo del río Uruguay, con latitud aproximada de $29^{\circ} 42^{\prime} 47$ LS y longitud $57^{\circ} 05^{\prime} 24$ LW; la región se completa con otros catorce municipios de los departamentos de Paso de los Libres, Monte Caseros, Curuzú Cuatiá y Mercedes. Es la cabecera del departamento homónimo, que incluye además las localidades de Tapebicuá, Parada Pucheta y Bonpland(Plan Estratégico de Ordenamiento Territorial del Municipio de Paso de los Libres, 2013) y dista de la capital Correntina en $362 \mathrm{Km}$.

La ciudad objeto de estudio es la cabecera de uno de los once (11) municipios de primera categoría con que cuenta la provincia que está constituida además por otros quince (15) de segunda categoría y treinta y nueve (39) de tercera categoría ${ }^{4}$.

Según el Censo Nacional de Población, Hogares y Viviendas 2010 el municipio de Paso de los Libres contaba en el año 2010 con una población de 45.805 habitantes (INDEC, 2010) ubicándose como el tercer municipio de la provincia con mayor número de habitantes, siguiendo a Corrientes y Goya.Asimismo en base a las proyecciones y estimaciones del mismo INDEC, al año 2018, el municipio estaría alcanzando una población total de 49.500 habitantes (INDEC, 2018).

"La mayor concentración de población se da en toda la extensión del municipio de Paso de los Libres. Dos factores inciden fundamentalmente en ello, la presencia del río Uruguay y la vecina ciudad de Uruguayana, que por su vínculo genera uno de los ejes más dinámicos de población, bienes y

Publicado en formato digital: Agrim. Prof. Laura Fabiana Gomez. CAMBIOS DE USOS DE SUELO EN PASO DE LOS LIBRES, CORRIENTES, ARGENTINA ENTRE 1990 Y 2016. Impacto del Proceso de Expansión Urbana. Revista Geográfica Digital. IGUNNE. Facultad de Humanidades. UNNE. Año 15. № 30. Julio - Diciembre 2018. ISSN 1668-5180 Resistencia, Chaco.

En: http://hum.unne.edu.ar/revistas/geoweb/default.htm 
servicios, concentrando el 96,58\% de la población urbana." (Plan Estratégico de Ordenamiento Territorial del Municipio de Paso de los Libres, 2012:44)

Mapa 1: Localización de la Provincia de Corrientes en Argentina. Localización de la Ciudad de Paso de los Libres en la Provincia de Corrientes

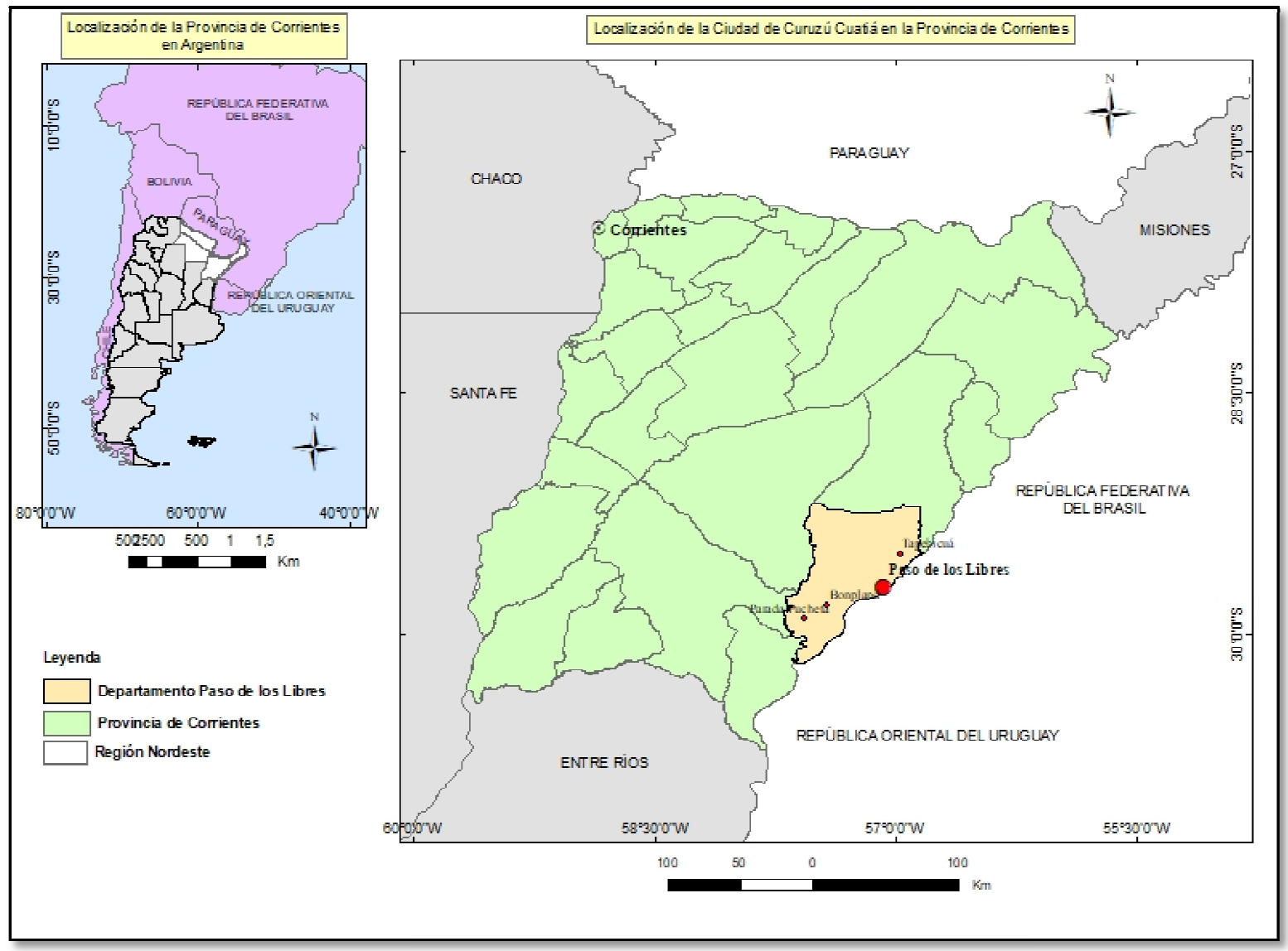

Fuente: Elaboración propia sobre la base de archivos vectoriales del Instituto Geográfico Nacional (IGN)

En el gráfico 1 se ha incluido la población de las ciudades que según el Censo 2010 registraron más de 2.000 habitantes en la provincia de Corrientes, allí se puede apreciar la conformación del sistema de ciudades, la importancia cuantitativa de la capital y la posición relativa de Paso de los Libres. Se evidencia la primacía que, por su tamaño poblacional, ejerce la ciudad capitalina ya que alberga alrededor de un tercio de los habitantes de la provincia y tiene cuatro veces más población que la segunda ciudad de la red urbana que es Goya y ocho veces más población que Paso de los Libres. No obstante, la posición geográfica de esta última ciudad en la región centro-sur 5 de la provincia y a orillas del río Uruguay es estratégica dada la presencia de uno de los más grandes puertos secos del país y un paso importante de conexión entre países integrantes del MERCOSUR, razón por la cual su relevancia es significativa tanto a nivel local como regional. 
Gráfico 1: Paso de los Libres en el Sistema Urbano Correntino. Cantidad de habitantes en ciudades más de 2.000 habitantes- de la Provincia de Corrientes

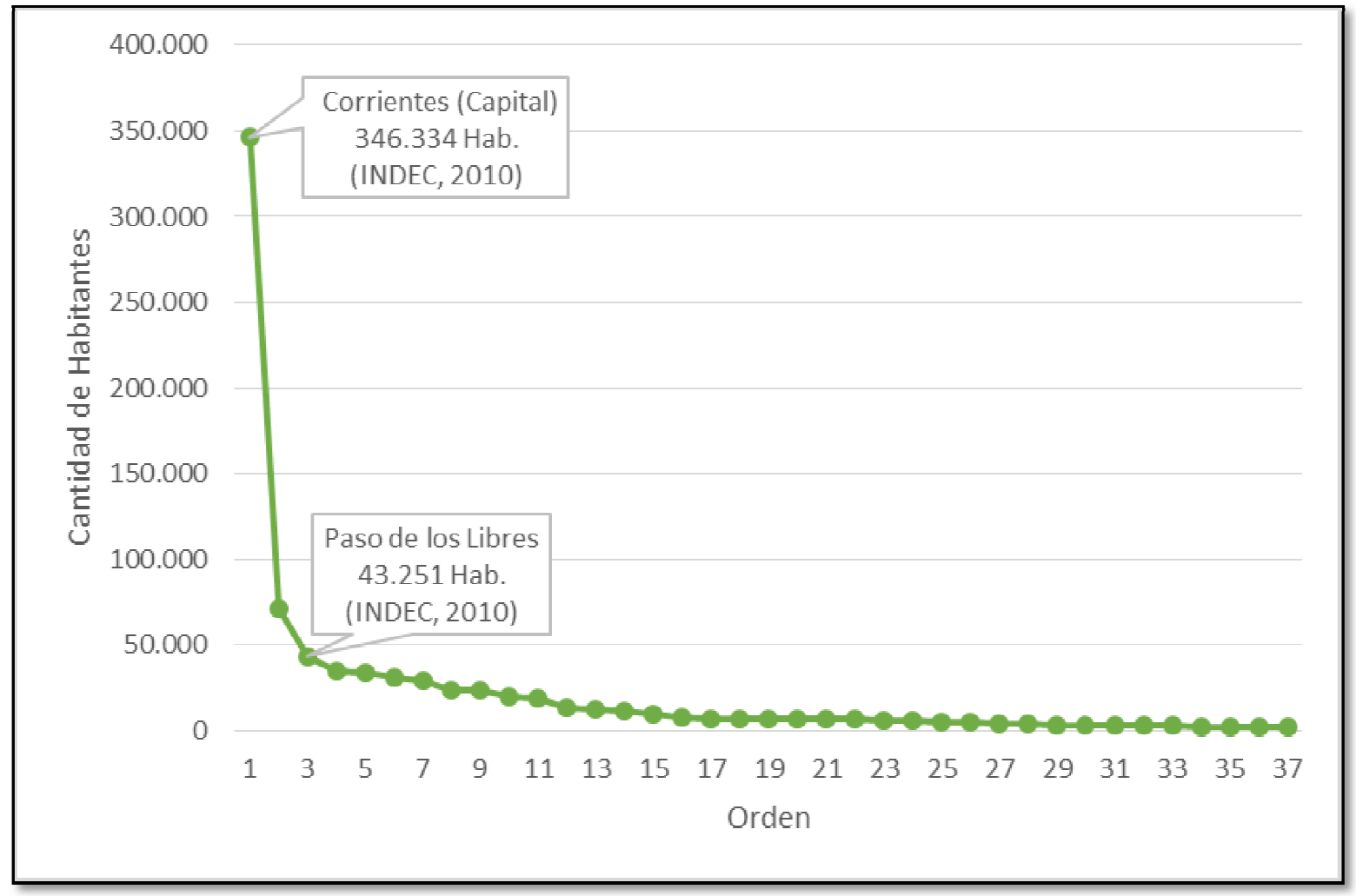

Fuente: Elaboración propia en base a datos del Censo Nacional de Población, Hogares y Viviendas, 2010, procesado con Retadam+SP.

La planta urbana de la ciudad se situó sobre el margen izquierdo del río Uruguay, frente a la ciudad brasileña de Uruguayana (Mapa 2) y se encuentra conectada a ella mediante el puente internacional "Agustin P. Justo - Getulio Vargas" desde el 21 de mayo de 1947. Está limitada por los arroyos Yatay al noreste, La Despedida al Noroeste y Porá al Oeste; al Sur la ciudad limita con el río Uruguay que la separa de la República Federativa del Brasil.

Mediante un primer análisis visual, es posible apreciar que en la actualidad el área urbanizada se encuentra dividida en dos sectores separados por el arroyo La Despedida. Por otro lado, las vías del ferrocarril General Urquiza se emplazan también como una barrera que fragmenta el espacio urbano. Hacia el sur, el espacio urbano alcanzó las mismas, y en determinados sectores, aunque en forma fragmentada, la ha traspasado. De forma similar, en cercanías de la Ruta Nacional $N^{\circ} 117$ se pueden ver sectores que comienzan a urbanizarse. Es posible además visualizar en el interior del área urbana consolidada intersticios o superficies vacías correspondientes a inmuebles de dominio del estado nacional 0 de dominio particular como así también superficies destinadas a barrios militares ${ }^{6}$, asimismo se aprecia la existencia de espacios urbanos incipientes, linderos al arroyo La Despedida donde se encuentran las menores alturas s.n.m. ${ }^{7}$.

Publicado en formato digital: Agrim. Prof. Laura Fabiana Gomez. CAMBIOS DE USOS DE SUELO EN PASO DE LOS LIBRES, CORRIENTES, ARGENTINA ENTRE 1990 Y 2016. Impacto del Proceso de Expansión Urbana. Revista Geográfica Digital. IGUNNE. Facultad de Humanidades. UNNE. Año 15. № 30. Julio - Diciembre 2018. ISSN 1668-5180 Resistencia, Chaco.

En: http://hum.unne.edu.ar/revistas/geoweb/default.htm 
Mapa 2: Planta Urbana de Paso de los Libres.

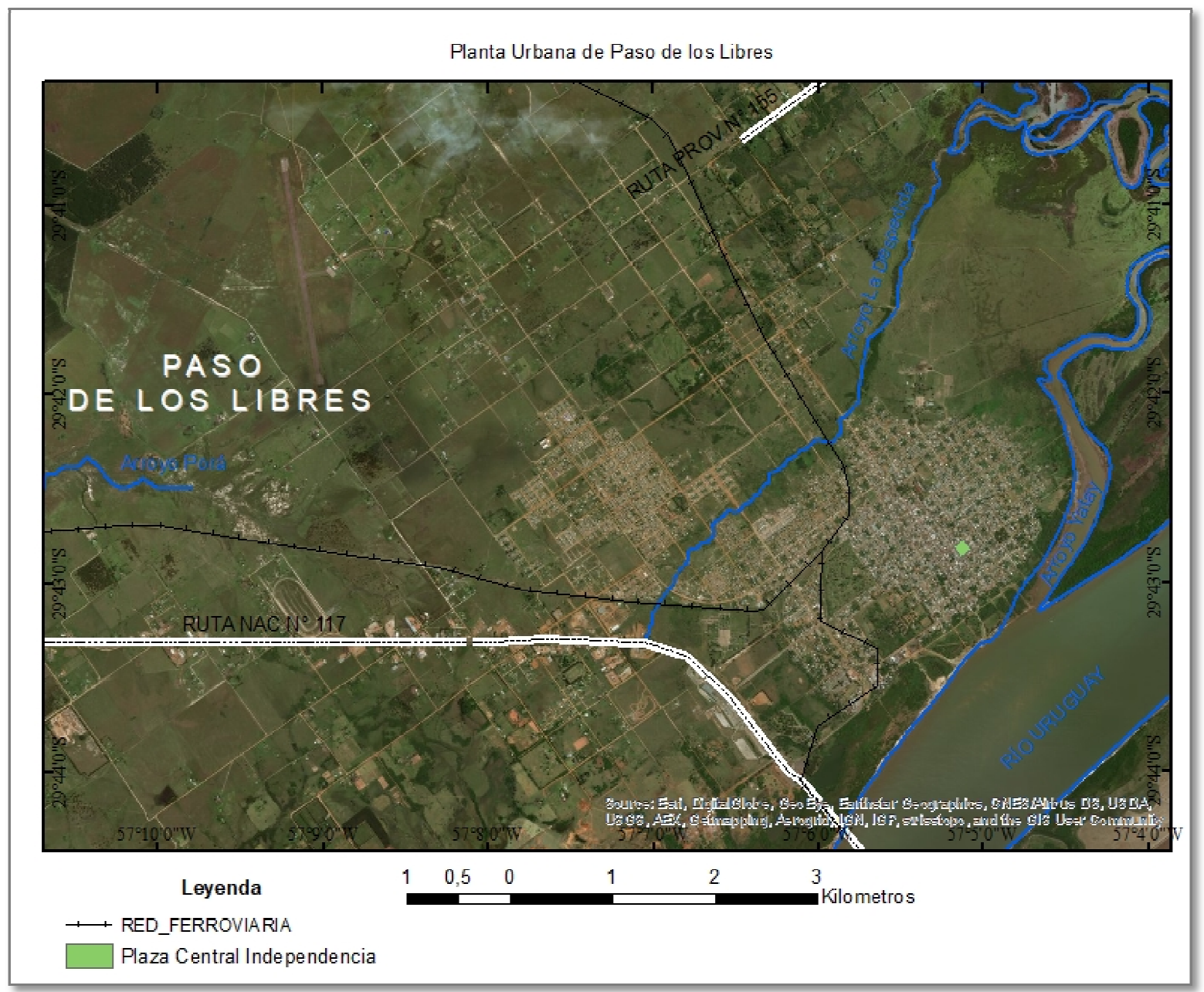

Fuente: Integración en base a SIG 250-IGN y GoogleEarth.

A través de las imágenes satelitales, los planos catastrales, la indagación en terreno y lo expuesto en el párrafo anterior, es posible confirmar inicialmente que la ciudad de Paso de los Libres está adquiriendorasgos de ciudad dispersa y fragmentada combinando las iniciativas de viviendas o residencias privadas con las propuestas de planes habitacionales estatales, razón por la cual, este modelo, tiende a acentuarse. Es por ello que esta contribución cobra relevancia ya que la información lograda permitirá fortalecer esta idea preliminar.

\section{MATERIALES Y METODOS}

Según Buzai "la Geografía actual posee nuevas herramientas para la gestión del territorio a partir del uso de tecnologías digitales que le han dado una flexibilidad propia que demandan las situaciones cambiantes de la actualidad" (Buzai, G, 2014:64). Es posible añadir a esto el uso de imágenes

Publicado en formato digital: Agrim. Prof. Laura Fabiana Gomez. CAMBIOS DE USOS DE SUELO EN PASO DE LOS LIBRES, CORRIENTES, ARGENTINA ENTRE 1990 Y 2016. Impacto del Proceso de Expansión Urbana. Revista Geográfica Digital. IGUNNE. Facultad de Humanidades. UNNE. Año 15. № 30. Julio - Diciembre 2018. ISSN 1668-5180 Resistencia, Chaco.

En: http://hum.unne.edu.ar/revistas/geoweb/default.htm 
satelitales como insumo para diseñar y llevar a cabo un estudio de índole urbana, contando de esta manera con un conjunto de instrumentos o recursos indispensables al momento de diseñar y llevar a cabo una investigación o estudio sobre expansión urbana. En particular, un estudio de este tipo (multitemporal), en el que se persigue la detección de cambios, convierte a las imágenes satelitales en materia prima fundamental.

Se han utilizado imágenes derivadas de la misión Landsat dadas sus idóneas resoluciones (espectral, espacial y temporal) útiles para estudios de carácter urbano, su continuidad en el tiempo y disponibilidad,entre otras ventajas propias de las imágenes de satélite como son el fácil acceso y la gratuidad.

En esta contribución se han utilizado imágenes satelitales de las plataformas Landsat 5, sensor TM (Thematic Mapper) que posee una resolución espacial de 30 metros en seis bandas multiespectrales y 120 metros en la banda térmica y Landsat 8, sensor OLI (Operational Land Imager), con nueve bandas espectrales de las cuales ocho poseen una resolución de 30 metros y una pancromática de 15 metros. Las imágenes que se utilizaron en esta contribución corresponden al path/row 225/081 de los días 08/06/1990 y 15/06/2016.

A las imágenes como principal fuente de datos se adicionaron otras fuentes tales como el imprescindible material bibliográfico que permitió conocer el origen y los antecedentes históricos de la ciudad y del municipio, profundizar el entendimiento del fenómeno global de la expansión urbana y advertir las diversas metodologías que se emplean para analizar este hecho con base en imágenes de satélite. También se han utilizado datos estadísticos proporcionados por el Instituto Nacional de Estadística y Censos (INDEC) de la Argentina que permitieron analizar el crecimiento poblacional de Paso de los Libres y, finalmente se emplearon geodatos de acceso libre disponibles en el sitio web del Instituto Geográfico Nacional (IGN) de Argentina que permitieron contextualizar espacialmente este estudio.

La información proporcionada por las fuentes fue tratadacon Sistemas de Información Geográfica (SIG/GIS), imprescindibles para procesar, tratar y generar nuevos. "Los SIG han generado importantes posibilidades al análisis espacial, a tal punto que pueden ser considerados como la tecnología geográfica más importante desde la aparición del mapa" (Chorley, 1987, citado en Buzai et. al, 2016:18).

La metodología seguida en este aporte se describe a continuación a modo de fases con el objeto de apreciar la secuencia de labores realizadas que permitieron arribar a los resultados que se expondrán más adelante.

$\checkmark$ Primera fase: lectura de antecedentes referidos a la fundación y crecimiento de la ciudad de Paso de los Libres que se complementó con la lectura de bibliografía referida al estudio y análisis de la expansión urbana mediante el uso de imágenes de satélite. Si bien estas actividades se incluyen en la primera fase, en términos reales, es una labor que se extendió a lo largo de toda la investigación.

$\checkmark$ Segunda fase: adquisición de las imágenes para ambos años considerados (1990 y 2016) a través de la página del Servicio Geológico de los Estados Unidos. (www.earthexplorer.usgs.gov, fecha de visita: 28 de junio de 2016).

$\checkmark$ Tercera fase:recorte o selección del ejido urbano de la ciudad y sus alrededores, en ambos momentos, utilizando para ello una máscara basada en el ejido urbano provisto por el IGN (www.ign.gob.ar, fecha de visita: agosto de 2015). Con el fin de evitar que en el segundo periodo analizado la mancha urbana exceda la extensión delimitada porel IGN se decidió ampliarlo en 1500 metrosutilizando para ello un buffer ${ }^{8}$ de polígono.

$\checkmark$ Cuarta fase: mejoramiento visual de las imágenes, en ese caso se ensayaron numerosas composiciones y se alcanzó el mejor detalle y discriminación de las cubiertas en las composiciones 753-Landsat 5 -TM y la 764 -Landsat 8-OLI- (Mapa 3), cuya resolución espacial se conservó en $30 \mathrm{~m}$.

Publicado en formato digital: Agrim. Prof. Laura Fabiana Gomez. CAMBIOS DE USOS DE SUELO EN PASO DE LOS LIBRES, CORRIENTES, ARGENTINA ENTRE 1990 Y 2016. Impacto del Proceso de Expansión Urbana. Revista Geográfica Digital. IGUNNE. Facultad de Humanidades. UNNE. Año 15. № 30. Julio - Diciembre 2018. ISSN 1668-5180 Resistencia, Chaco.

En: http://hum.unne.edu.ar/revistas/geoweb/default.htm 
Mapa 3: Visualización del Ejido Urbano de la Paso de los Libres en los años 1990 y 2016.

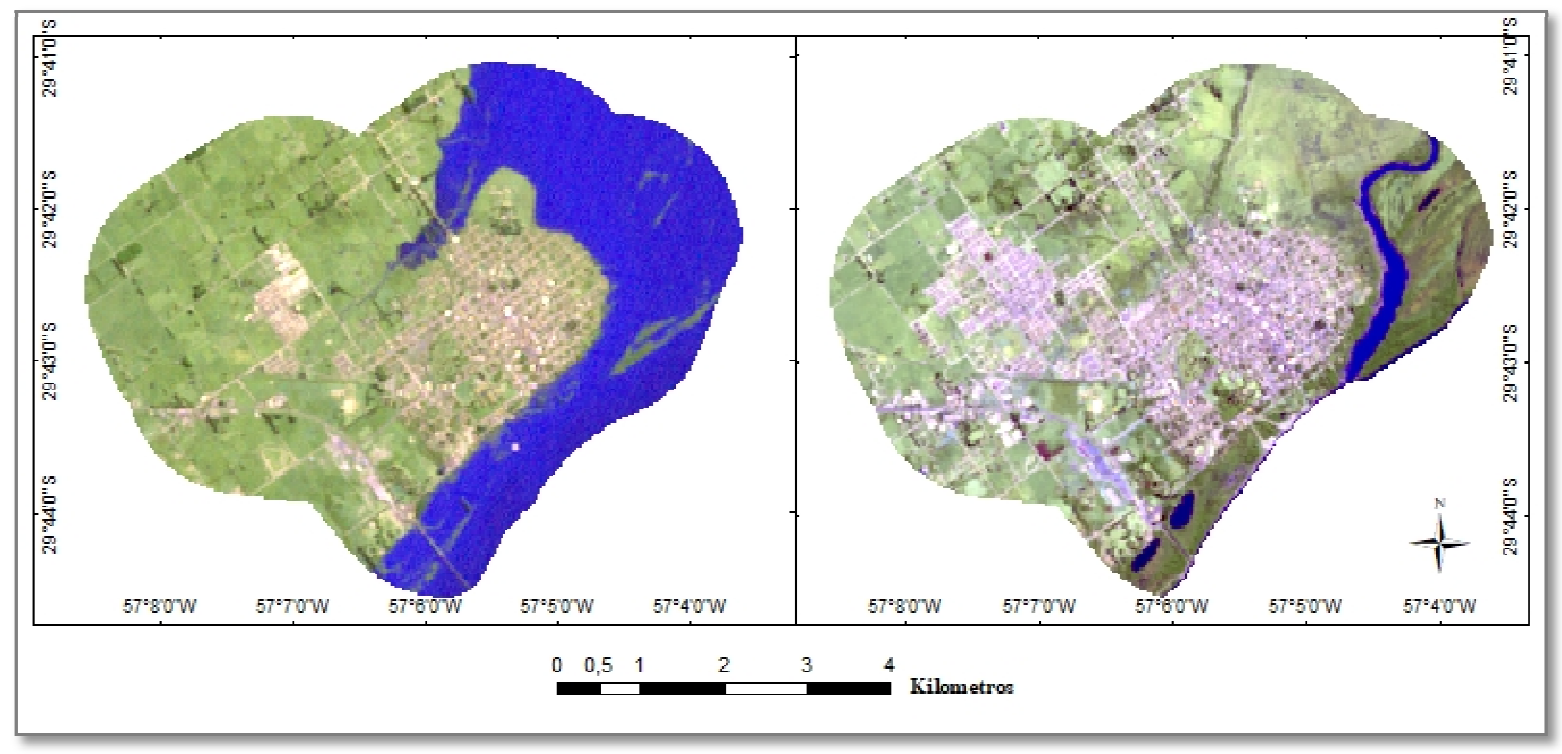

Fuente: Elaboración propia.

$\checkmark$ Quinta fase:análisis de firmas espectrales, identificación de cubiertas y adquisición de muestras. Esta etapa consistió en establecer las categorías o cubiertas más representativas del área de estudio. Se consideraron las particularidades de Paso de los Libres en cuanto a la presencia de cuerpos y cursos de agua y los antecedentes relevantes para este tipo de estudios. Se detallan a continuación las definiciones de las clases consideradas (Tabla 1).

Luego de esa labor se adquirieron las muestras espectrales en cada momento de análisis a partir de áreas en las que se visualizan las categorías con la menor confusión posible.En este sentido "la observación previa en el espectro electromagnético del comportamiento de algunas cubiertas normalmente asociadas al ámbito urbano (cemento, asfalto, tierra, zinc, tejas, etc.), puede arrojar información muy valiosa para ayudar a discriminarlas en la imagen" (Cardozo et. al, 2013: 4)

Tabla 1: Categorías presentes en la clasificación supervisada

\begin{tabular}{|c|c|}
\hline $\begin{array}{l}\text { Área Urbana } \\
\text { Consolidada. } \\
\text { AUC }\end{array}$ & $\begin{array}{l}\text { El área urbana comprende todo aquel fraccionamiento en manzanas o } \\
\text { unidades equivalentes, determinadas total o parcialmente por calles, } \\
\text { como asimismo aquellas parcelas que no estando fraccionadas estén } \\
\text { rodeadas parcial o totalmente por fraccionamiento en manzanas o } \\
\text { unidades equivalentes, destinadas a asentamientos humanos } \\
\text { intensivos, en los que se desarrollan usos vinculados con la } \\
\text { residencia, las actividades terciarias y de producción compatibles. } \\
\text { Aquéllas con más del } 50 \% \text { de sus parcelas edificadas y con los } \\
\text { servicios de alumbrado público, agua potable y calles pavimentadas } \\
\text { y/o mejoradas formarán parte del área urbana consolidada } 9\end{array}$ \\
\hline
\end{tabular}

Publicado en formato digital: Agrim. Prof. Laura Fabiana Gomez. CAMBIOS DE USOS DE SUELO EN PASO DE LOS LIBRES, CORRIENTES, ARGENTINA ENTRE 1990 Y 2016. Impacto del Proceso de Expansión Urbana. Revista Geográfica Digital. IGUNNE. Facultad de Humanidades. UNNE. Año 15. № 30. Julio - Diciembre 2018. ISSN 1668-5180 Resistencia, Chaco.

En: http://hum.unne.edu.ar/revistas/geoweb/default.htm 


\begin{tabular}{|l|l|}
\hline $\begin{array}{l}\text { Área Periurbana. } \\
\text { AP }\end{array}$ & $\begin{array}{l}\text { - Área a consolidar: Aquéllas con menos del } 50 \% \text { de sus parcelas } \\
\text { edificadas y con servicio de alumbrado público o de agua potable, } \\
\text { como mínimo. } \\
\text { - De expansión: Aquélla contigua a las anteriores con posibilidades de } \\
\text { conexión a redes de provisión de servicios, vinculados con vía o calle } \\
\text { pública existente y que no supere el } 20 \% \text { de la superficie total de las } \\
\text { otras sub-áreas }{ }^{10} .\end{array}$ \\
\hline $\begin{array}{l}\text { Infraestructura. } \\
\text { INF }\end{array}$ & $\begin{array}{l}\text { Considera las calles, rutas provinciales y nacionales, vías férreas, } \\
\text { aeropuertos e infraestructura relacionada con las actividades rurales. }\end{array}$ \\
\hline $\begin{array}{l}\text { Cuerpos y } \\
\text { cursos de agua. } \\
\text { CCA }\end{array}$ & $\begin{array}{l}\text { Cursos de agua permanente y no permanente. } \\
\text { Áreas o espacios anegables e inundables. }\end{array}$ \\
\hline $\begin{array}{l}\text { Áreas verdes y } \\
\text { cobertura } \\
\text { vegetal urbana. } \\
\text { AVCVU }\end{array}$ & $\begin{array}{l}\text { Espacio con predominio de parques, plazas, jardines, paseos, } \\
\text { parterres, plantíos, vegetación arbórea. También incluyen los parterres } \\
\text { y jardines centrales en vías públicas. }\end{array}$ \\
\hline
\end{tabular}

Fuente: Elaboración propia

Sexta fase: clasificación de imágenes, en esta etapa mediante la aplicación de un clasificador automatizado de tipo supervisado que emplea el criterio de máxima probabilidad, el cual permite ajustar con mayor robustez la disposición original de los datos (Molina, 1998, citado en López Vázquez y Plata Rocha, 2009), se procedió a clasificar temáticamente las cubiertas. Dicho clasificador usa como base a las firmas espectrales obtenidas de las muestras adquiridas, para ambos momentos. El problema de clasificar imágenes para la obtención de áreas urbanas es la mezcla de elementos que dentro de ella se encuentran y la confusión de firmas espectrales que de ellos se deriva (López Vázquez y Plata Rocha, 2009: 90). Debido a esta situación es que esta etapa fue la que requirió de la mayor cantidad de ensayos posibles hasta alcanzar un resultado que refleje de la mejor manera posible la realidad analizada. En esta fase se utilizaron como apoyo imágenes de Google Earth de mayor resolución espacial, las cuales nos auxiliaron a la discriminación entre las clases informacionales al momento de recoger las muestras.

$\checkmark$ Séptima fase: análisis multitemporal para detectar cambios y variabilidad entre clases.La etapa final consiste en medir los cambios, para ello se requiere de la cuantificación de la superficie que abarca cada categoría en cada momento, así se calcula el cambio neto de cada clase, las ganancias, pérdidas y persistencia que manifiesta cada categoría y el cambio total. Por otro lado también se reconocen los intercambios, es decir la superficie que siendo de una categoría pasa a otra y de esta última a la primera y, finalmente, las transiciones entre clases. Con el propósito de ser más explícitos a continuación se definen cada uno de estos conceptos.

Tabla 2: Definición de conceptos clave en el análisis de cambios de uso del suelo.

\begin{tabular}{|l|l|}
\hline Cambio neto & $\begin{array}{l}\text { Respecto de una categoría de análisis } X_{i}: \\
\text { Valor absoluto de la sustracción entre la superficie de la categoría } X_{i} \text { en } \\
\text { un tiempo } T_{2} \text { (segundo momento considerado), respecto de un tiempo } \\
\text { anterior } T_{1} \text { (primer momento considerado). } \\
C N\left(X_{i}\right)=\left|\operatorname{Sup}(X i)_{T_{2}}-\operatorname{Sup}(X i)_{T_{1}}\right|\end{array}$ \\
\hline
\end{tabular}

Publicado en formato digital: Agrim. Prof. Laura Fabiana Gomez. CAMBIOS DE USOS DE SUELO EN PASO DE LOS LIBRES, CORRIENTES, ARGENTINA ENTRE 1990 Y 2016. Impacto del Proceso de Expansión Urbana. Revista Geográfica Digital. IGUNNE. Facultad de Humanidades. UNNE. Año 15. № 30. Julio - Diciembre 2018. ISSN 1668-5180 Resistencia, Chaco.

En: http://hum.unne.edu.ar/revistas/geoweb/default.htm 


\begin{tabular}{|c|c|}
\hline Persistencia & $\begin{array}{l}\operatorname{Pers}\left(X_{i}\right) \text { : Porción de superficie de la categoría de análisis } X_{i} \text { que se } \\
\text { mantuvo constante entre } T_{1} \text { (primer momento considerado) y } T_{2} \text {. } \\
\text { (segundo momento considerado) }\end{array}$ \\
\hline Ganancia & $\begin{array}{l}\text { Respecto de una categoría de análisis } X_{i} \text { : } \\
\text { Gan }\left(X_{i}\right) \text { : Porción de superficie de la categoría de análisis } X_{i} \text { en el } \\
\text { tiempo } T_{2} \text { (segundo momento considerado) que en el tiempo } T_{1} \text { (primer } \\
\text { momento considerado) fue de alguna otra superficie } \\
X_{1}, X_{2}, \ldots X_{j}, \ldots X_{n} \text {, con } i \neq j . \\
\text { El valor de la misma se calculará mediante la diferencia: } \\
\qquad \operatorname{Sup}\left(X_{i}\right)_{T_{2}}-\operatorname{Pers}\left(x_{i}\right)\end{array}$ \\
\hline Pérdida & $\begin{array}{l}\text { Respecto de una categoría de análisis } X_{i} \text { : } \\
\operatorname{Perd}\left(X_{i}\right) \text { : Porción de superficie de la categoría de análisis } X_{i} \text { en el } \\
\text { tiempo } T_{1} \text { (primer momento considerado) que en el tiempo } \\
T_{2} \text { (segundo momento considerado) fue de alguna superficie } \\
X_{1}, X_{2}, \ldots X_{j}, \ldots X_{n} \text {, con } i \neq j . \\
\text { El valor de la misma se calculará mediante la diferencia: } \\
\qquad \operatorname{Sup}\left(X_{i}\right)_{T_{1}}-\operatorname{Pers}\left(x_{i}\right)\end{array}$ \\
\hline Cambio total & $\begin{array}{l}\text { Respecto de una categoría de análisis } X_{i} \text { : } \\
\text { Sumatoria de superficie ganada por la categoría } X_{i} \text { y la superficie } \\
\text { perdida por la categoría } X_{i} \text { entre el } T_{2} \text { (segundo momento } \\
\text { considerado) y el } T_{1} \text { (primer momento considerado). } \\
\qquad C T\left(X_{i}\right)=\operatorname{Gan}\left(X_{i}\right)+\operatorname{Perd}\left(X_{i}\right)\end{array}$ \\
\hline Intercambio & $\begin{array}{l}\text { Respecto de una categoría de análisis } X_{i} \text { : } \\
\text { Doble producto entre el valor mínimo de la superficie ganada por la } \\
\text { categoría } X_{i} y \text { la superficie perdida por la categoría } X_{i} \text { entre el } T_{2} \\
\text { (segundo momento considerado) y el } T_{1} \text { (primer momento } \\
\text { considerado). } \\
\qquad \operatorname{Inter}\left(X_{i}\right)=2 \cdot \operatorname{mín}\left\{\operatorname{Gan}\left(X_{i}\right) ; \operatorname{Perd}\left(X_{i}\right)\right\}\end{array}$ \\
\hline $\begin{array}{l}\text { Transiciones a } \\
\text { una categoría } j\end{array}$ & $\begin{array}{l}\text { Respecto de una categoría de análisis } X_{i} \text { : } \\
\text { Superficie de la categoría } X_{i} \text { en } T_{1} \text { (primer momento considerado) que } \\
\text { se transformó en otra categoría }\left(X_{2}, X_{3}, \ldots, X_{n}\right) \text { en el } T_{2} \text { (segundo } \\
\text { momento considerado). } \\
\qquad \text { Trans }\left(X_{i}\right)_{T_{1}}=\left(X_{j}\right)_{T_{2}} ; i \neq j\end{array}$ \\
\hline
\end{tabular}

Fuente: Adaptado de Pontius, R. et al., 2004.

Además, se complementó este procedimiento con el análisis de una matriz de tabulación cruzada entre los mapas de diferentes fechas basada en la metodología desarrollada por Pontius, $R$. et al (2004). En dicha matriz, que se incluye más adelante como resultado (tabla 4), las persistencias o pixeles que no sufrieron modificaciones, se ubican en la diagonal principal y en las celdas restantes 
se ubican los píxeles, si los hubiera, que en el año 1990 fueron de una clase y en el año 2016 se clasificaron dentro de otra categoría. Sumando todos los píxeles de una categoría en el año 2016 y restándole las persistencias de dicha categoría es posible obtener la ganancia experimentada por la misma. De manera análoga pero trabajando con los píxeles de una clase en el año 1990 y sustrayéndoles los elementos de la diagonal principal, es posible obtener las pérdidas experimentadas por cada clase. Por otro lado, sumando las ganancias y las pérdidas de cada categoría se obtiene el cambio total (real) y calculando el doble del mínimo de las ganancias o las pérdidas se obtienen los intercambios experimentados por cada categoría (Pontius, R, et al., 2004: 252-257). Cabe aclarar que los valores obtenidos pueden expresarse tanto en número de píxeles como en su equivalente valor de superficie representada, como se presentan en los resultados de este trabajo.

\section{RESULTADOS}

\section{Crecimiento de la población y expansión del área urbana consolidada}

Del análisis de la información brindada por el INDEC obtenida a partir de los Censos Nacionales de Hogares y Viviendas de los años 1991 y 2010, y haciendo uso de las proyecciones y estimaciones realizadas por dicho Instituto, es posible afirmar que en 26 años la ciudad de Paso de los Libres ha incrementado su población en un $54,2 \%$, lo que en valores absolutos alcanza a unos 18.410 habitantes (Tabla 3).

Así mismo, haciendo uso de las imágenes clasificadas en ambos años es posible analizar los cambios en el AUC en 26 años. En el año 1990, la superficie ocupada por dicha categoría era de 196,65hectáreas mientras que en el año 2016 la misma ascendía 616,86 hectáreas, es decir hubo un incremento del 213,68\%(420,21 hectáreas). (Tabla 3)

Tabla 3: Población de la Ciudad de Paso de los Libres y superficie del AUC en los años 1990 y 2016.

\begin{tabular}{|c|c|c|c|c|c|c|}
\hline \multicolumn{2}{|c|}{1990} & 2010 & \multicolumn{2}{c|}{2016} & $\begin{array}{c}\text { Incremento en 26 años } \\
\text { (en porcentaje) }\end{array}$ \\
\hline Habitantes & $\begin{array}{c}\text { Superficie } \\
\text { del AUC }\end{array}$ & Habitantes & Habitantes & $\begin{array}{c}\text { Superficie } \\
\text { del AUC }\end{array}$ & Habitantes & Superficie \\
\hline $33.967^{11}$ & 196,65 & 43.251 & 52.377 & 616,86 & $54,2 \%$ & $213,68 \%$ \\
\hline
\end{tabular}

Fuente: Elaboración propia en base a INDEC, 1991, INDEC, 2010 y Proyecciones y Estimaciones INDEC, 2017

Relacionando la población con la superficie de AUC es posible calcular la densidad poblacional en ambos años. De esta manera, para 1990 la densidad poblacional de Paso de los libres era de 172,7 habitantes por hectárea, mientras que en el año 2016 dicho valor fue de 84,91 habitantes por hectárea.Desde otra perspectiva, en el año 1990 este valor representa casi 58 metros cuadrados por persona, mientras que para el 2016 la superficie por cada habitante asciende a 117,17 metros cuadrados, reflejando una característica propia de las ciudades dispersas.

La inspección visual de las clasificaciones realizadas (Mapa 6) muestrauna clara expansión del AUC hacia el oeste y hacia el suroeste, siendo un factor de desarrollo importante la presencia de la Ruta Nacional $\mathrm{N}^{\circ}$ 117. La expansión del AUC se ha visto favorecida por la pavimentación de diversas calles que permitieron la interconexión desde el centro a un importante sector urbanizadoconformado principalmente por barrios planificados y construidos por el Instituto de Viviendas de Corrientes 
(INVICO), la instalación del puente sobre el arroyo La Despedida y la extensión del servicio de dos líneas de colectivos (Plan Estratégico de Ordenamiento Territorial del Municipio de Paso de los Libres, 2013:148-149).

Además, se evidencia una fuerte consolidación del área central incluso en sectores de bajas alturas próximos al arroyo Yatay y al arroyo La Despedida, y en los sectores aledaños a las vías del ferrocarril. (Mapa 6)

Mapa 6: Clasificación supervisada de la Ciudad de Paso de los Libres en los años 1990 y 2016.

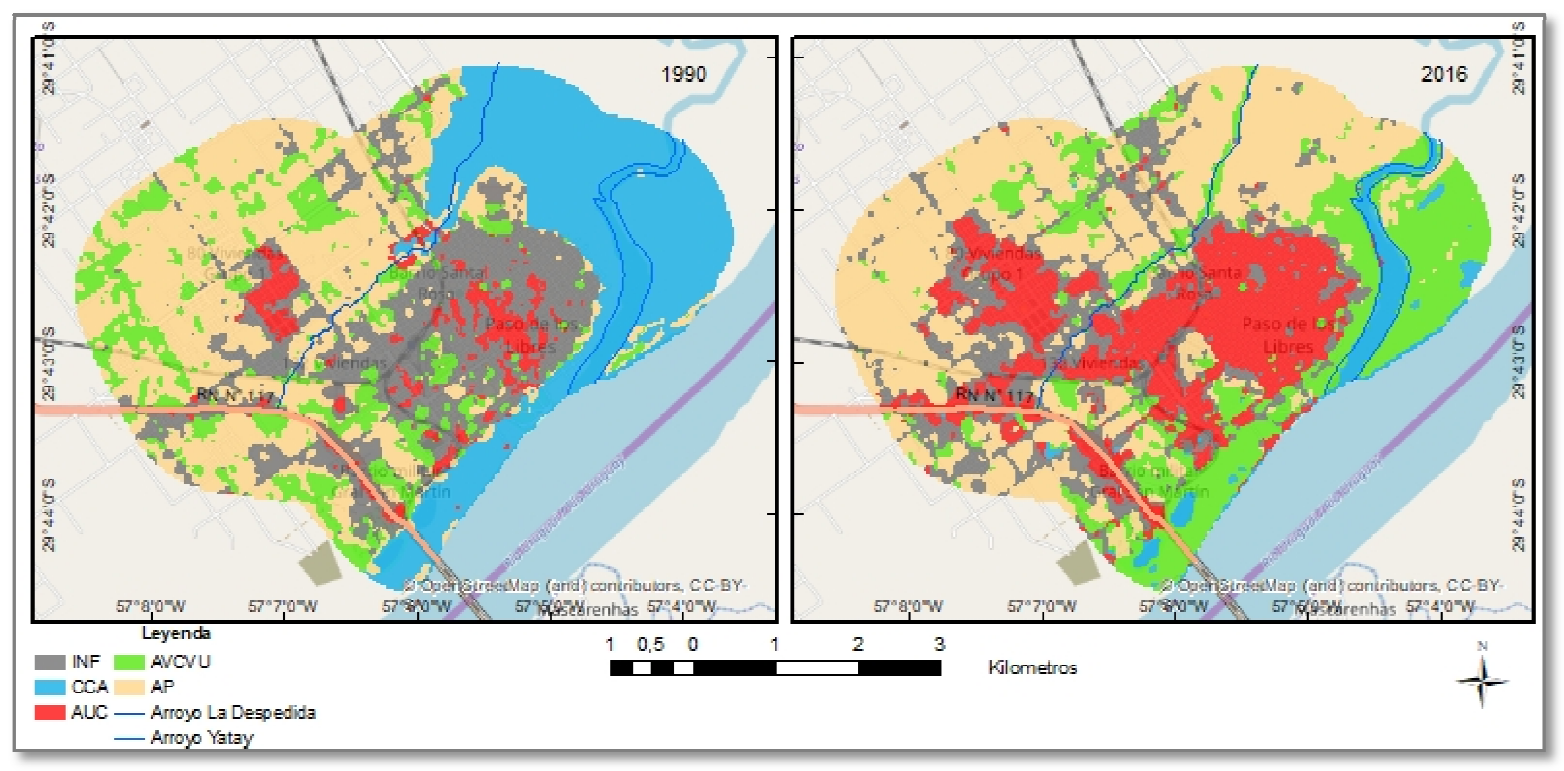

Fuente: Elaboración propia.

Variabilidad de las cubiertas según persistencia, ganancias, pérdidas, cambio neto y cambio total.

Mediante la matriz de tabulación cruzada (Tabla 4) se pueden comparar las imágenes clasificadas en dos momentos para conocer la dinámica que han experimentado en ese lapso de tiempo las clases o cubiertas analizadas.

Mirando los valores fuera de la diagonal principal de la matriz de tabulación cruzada, se puede apreciar el movimiento considerable que se da entre todas las categorías (transiciones).

En la diagonal principal de la tabla vemos la superficie de cada clase informacional que ha permanecido sin variaciones, estos valores muestran la estabilidad en las categorías, sobresale el AP y la INF, y son en general valores que dominan en la mayoría de las clases, incluso en aquellas en las que se produjo un cambio importante (Pontius, 2004). Al respecto es interesante resaltar el caso particular de la categoría CCA que no verifica la premisa anterior. En este caso, observar la espacialidad de las transiciones de los CCA al AVCVU y al AP (son las mayores) (Mapa 7) permite detectar o justificar el hecho de que tales valores se deben al incremento del espejo de agua debido a la creciente del RíoUruguay en el año 1990, que para la fecha de captura de la imágenes utilizadas en este estudio alcanzó los 10,87 metros ${ }^{12}$, en oposición a los 2,46 metros alcanzados en el año $2016^{13}$. 
Tabla 4: Matriz de tabulación cruzada (valores en hectáreas)

\begin{tabular}{|c|c|c|c|c|c|c|c|}
\hline & \multicolumn{6}{|c|}{2016} \\
\hline & & 는 & ঠ্ত & 일 & ऐ্ & $\frac{0}{4}$ & $\begin{array}{l}\bar{\Xi} \\
\stackrel{0}{0}\end{array}$ \\
\hline \multirow{6}{*}{ 욤 } & INF & 244,98 & 5,04 & 307,26 & 30,87 & 81,99 & 670,14 \\
\hline & CCA & 37,08 & 120,06 & 13,32 & 363,15 & 302,04 & 835,65 \\
\hline & AUC & 22,05 & 2,25 & 156,87 & 9,36 & 6,12 & 196,65 \\
\hline & AVCVU & 91,17 & 8,82 & 48,33 & 144,27 & 181,17 & 473,76 \\
\hline & AP & 213,39 & 5,58 & 91,08 & 129,96 & 550,17 & 990,18 \\
\hline & Total & 608,67 & 141,75 & 616,86 & 677,61 & 1121,49 & 3166,38 \\
\hline
\end{tabular}

Fuente: Elaboración Propia

Mapa 7: Transiciones de la categoría CCA a las categorías AP y AVCVU entre los años 1990 y 2016.

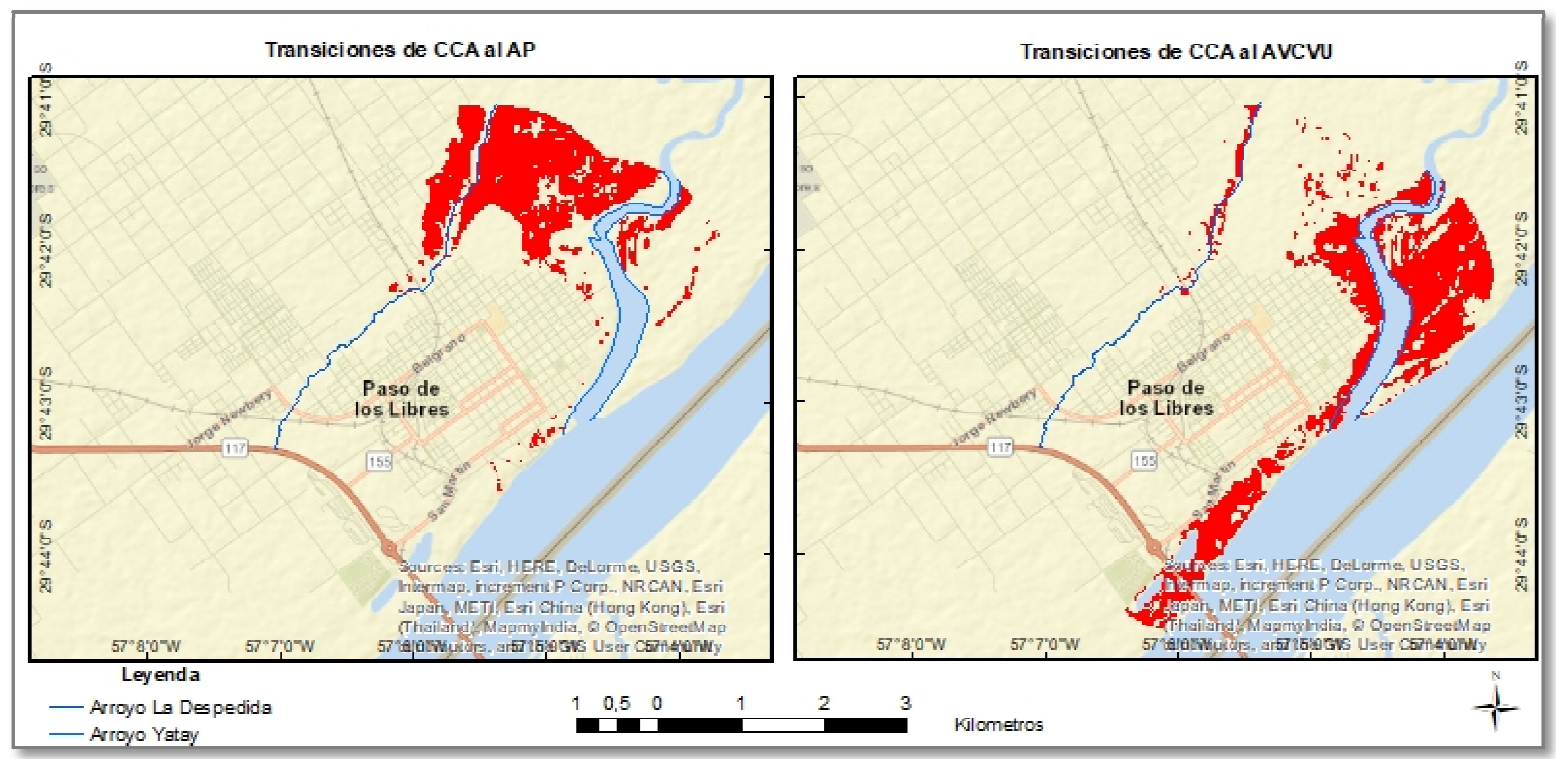

Fuente: Elaboración Propia

Los registros incluidos en la tabla 4 también permiten determinar las ganancias y pérdidas, útiles para el cálculodel cambio neto y el cambio total y de los intercambios entre categorías.

En otro orden de análisis el cambio neto de las categorías se aprecia en el Gráfico 2, allí vemosque las categorías AUC, AVCVU y AP son las que han aumentado su superficie en el periodo de tiempo

Publicado en formato digital: Agrim. Prof. Laura Fabiana Gomez. CAMBIOS DE USOS DE SUELO EN PASO DE LOS LIBRES, CORRIENTES, ARGENTINA ENTRE 1990 Y 2016. Impacto del Proceso de Expansión Urbana. Revista Geográfica Digital. IGUNNE. Facultad de Humanidades. UNNE. Año 15. № 30. Julio - Diciembre 2018. ISSN 1668-5180 Resistencia, Chaco.

En: http://hum.unne.edu.ar/revistas/geoweb/default.htm 
analizado $(68 \%, 30 \%$ y $12 \%$ respectivamente). A la inversa, los CCA y la INF disminuyeron su superficie en $490 \%$ y $10 \%$ respectivamente.

Gráfico 2: Cambio Neto por categoría entre 1990 y 2016 (valor expresados en porcentajes)

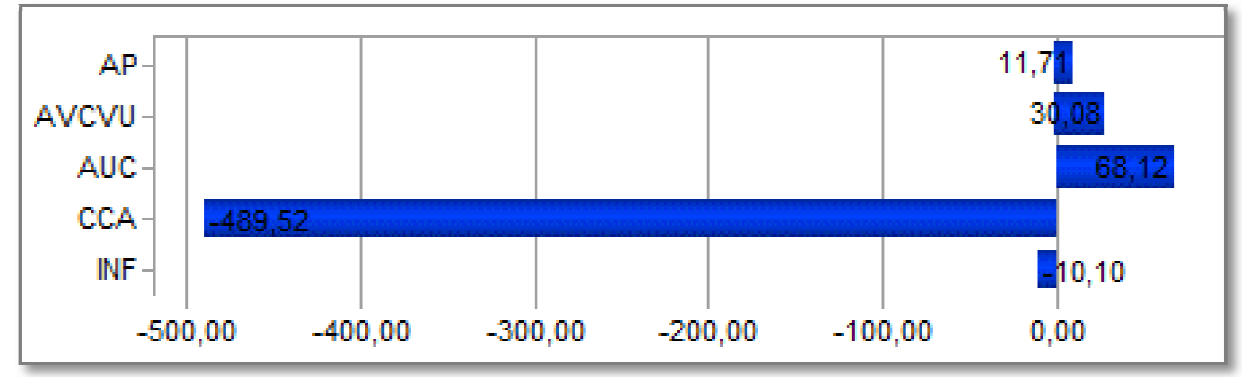

Fuente: Elaboración propia.

Tal como se definió en la tabla 2 el cambio neto resulta igual a la diferencia entre las ganancias y pérdidas que experimenta una cubierta en un lapso determinado (en valores absolutos), ello permite conocer cuán variable es la categoría analizada. Sin embargo este valor expresa el resultado final de la combinación entre superficie ganada y perdida, pero no detalla las proporciones de cada una de ellas. Por ejemplo, la categoría CCA es la que mayor cambio neto ha experimentado en términos absolutos, si el análisis se detuviera en esta afirmación se perdería el valor agregado de conocer que dicho valor es el mayor dada la gran cantidad de superficie perdida por el avance de otras (Gráfico 3). De manera inversa, las categorías AP e INF han sido las de menor cambio neto, debido a que han experimentado valores altos tanto en ganancias como en pérdidas (AP ha ganado 571 hectáreas y perdido 440 hectáreas e INF ha ganado 363 hectáreas y perdido 425 hectáreas). Por lo tanto el análisis debe ser integral.

Gráfico 3: Ganancias y pérdidas por categorías entre 1990 y 2016 (valor expresados en hectáreas)

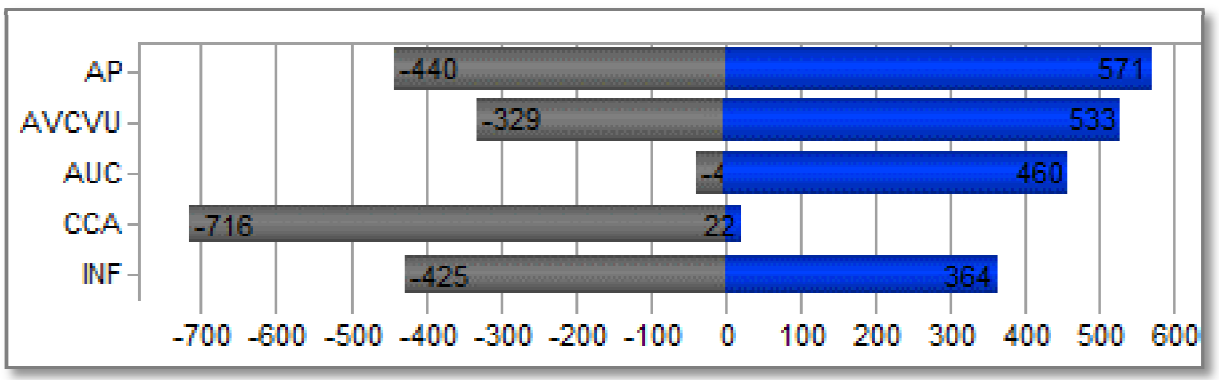

Fuente: Elaboración propia.

Por otra parte, analizando los intercambios de superficie entre coberturas y teniendo en cuenta que éstos expresanel doble del mínimo entre la ganancia o la pérdida de una categoría (up supra, tabla 2), de acuerdo con lo expuesto en el párrafo anterior, no existe coincidencia entre la cobertura de mayor cambio neto y la cobertura de mayor intercambio, ya que, como vimos, la categoría CCA es la mayor cambio neto, mientras que la categoría AP es la de mayor intercambio (tabla 5).Siguiendo con el análisis sobre el cambio neto e intercambio, si se tomara en cuenta solamente el valor de cambio neto de las categorías INF, AVCVU y AP entoncesno se estaría considerando la dinámica real que experimentan estas coberturas que sí se ve reflejada en el cambio total (Cambio neto + Intercambio).

Publicado en formato digital: Agrim. Prof. Laura Fabiana Gomez. CAMBIOS DE USOS DE SUELO EN PASO DE LOS LIBRES, CORRIENTES, ARGENTINA ENTRE 1990 Y 2016. Impacto del Proceso de Expansión Urbana. Revista Geográfica Digital. IGUNNE. Facultad de Humanidades. UNNE. Año 15. № 30. Julio - Diciembre 2018. ISSN 1668-5180 Resistencia, Chaco.

En: http://hum.unne.edu.ar/revistas/geoweb/default.htm 
Sintetizando todo lo dicho, el valor de cambio neto experimentado por la totalidad del área de estudio es de 1500 hectáreas aproximadamente, no obstante este valor no refleja la dinámica real que se identifica mediante el cambio total que es de 3900 hectáreas aproximadamente.

Tabla 5: Cambios y transiciones entre Categorías (Valores en hectáreas)

\begin{tabular}{|c|c|c|c|c|c|c|}
\hline & 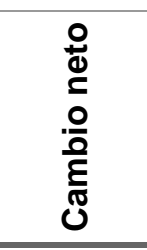 & $\begin{array}{l}\frac{\pi}{0} \\
0 \\
\frac{c}{0} \\
\frac{0}{0} \\
\frac{0}{0} \\
\frac{0}{0}\end{array}$ & $\begin{array}{l}\frac{\pi}{0} \\
\frac{\pi}{\pi} \\
\frac{\pi}{\pi} \\
0\end{array}$ & $\begin{array}{l}\frac{\pi}{0} \\
\frac{0}{0} \\
\frac{0}{0}\end{array}$ & 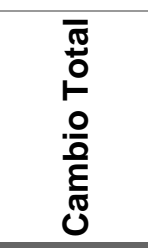 & 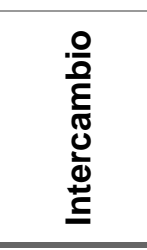 \\
\hline INF & 61,47 & 244,98 & 363,69 & 425,16 & 788,85 & 727,38 \\
\hline CCA & 693,9 & 120,06 & 21,69 & 715,59 & 737,28 & 43,38 \\
\hline AUC & 420,21 & 156,87 & 459,99 & 39,78 & 499,77 & 79,56 \\
\hline AVCVU & 203,85 & 144,27 & 533,34 & 329,49 & 862,83 & 658,98 \\
\hline AP & 131,31 & 550,17 & 571,32 & 440,01 & 1011,33 & 880,02 \\
\hline Total & 1510,74 & 1216,35 & 1950,03 & 1950,03 & 3900,06 & 2389,32 \\
\hline
\end{tabular}

Fuente: Elaboración Propia.

\section{Dinámica del área urbana consolidada (AUC)}

En el periodo de veintiséis añosla ganancia del suelo urbano consolidado fue de 460 hectáreas, este ascenso de la categoría surge a partir de la pérdida de superficie en todas las otras coberturas que se han analizado. Asimismo, en dicho periodo,el AUC perdió aproximadamente 40 hectáreas, lo que arroja un cambio neto de 420 hectáreas.

En el gráfico 4 se puede visualizar cómo las diversas categorías aportan al incremento final (cambio neto) de la clase urbana consolidada. En efecto, es posible identificar que la categoría INF, la que además de estar conformada por la red vial y ferroviaria, incluye infraestructura asociada a la actividad del comercio mayorista (depósitos y galpones), almacenes y depósitos de medianas y grandes extensiones cuyo uso es orientado a las labores rurales y a los servicios urbanos, es la que ha experimentado en mayor medida el impacto del avance del AUC, convirtiéndose en el principal tributario al cambio neto del AUC (285 hectáreas). En menor medida, también han contribuido en este cambio el AP (85 hectáreas), las AVCVU (39 hectáreas) y los CCA (11 hectáreas)(gráfico 4). 
Gráfico 4: Contribución de cada categoría al cambio neto del Área Urbana Consolidada entre 1990 y 2016 (valores en hectáreas).

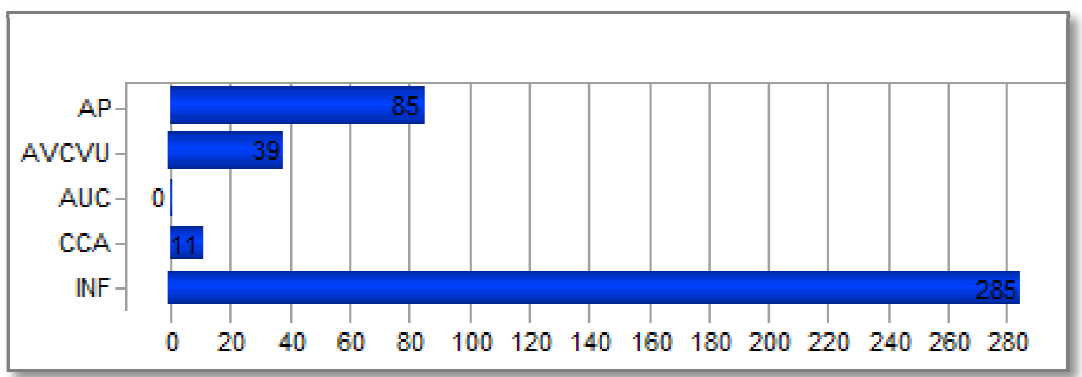

Fuente: Elaboración Propia

En cuanto a la espacialidad de los cambios del AUC es posible generalizar señalando que los "nuevos" espacios clasificados en 2016 como AUC se encuentran distribuidos, por un lado,alrededor de la superficie de persistencia de dicha categoría, ganando continuidad hasta las proximidadesdel arroyo La Despedida y acercándose al arroyo Yatay. Se pueden apreciar también ganancias en los espacios "internos" o intersticios del AUC de 1990, contribuyendo a la consolidación de la misma. Es posible además ver importantes espacios ganados en el sector suroeste cercanos a la Ruta Nacional $\mathrm{N}^{\circ} 117$ como así también en el sector oeste dando continuidad a un área de persistencia en ese sector.

En cuanto a las pérdidas de AUC, 40 hectáreas, no se distingue un patrón de localización específico, son espacios dispersos en toda el área aunque con mayor presencia en el norte a la vera del ferrocarril. 
Mapa 7: Espacialidad de las ganancias, pérdidas en la categoría Área Urbana Consolidada (AUC).

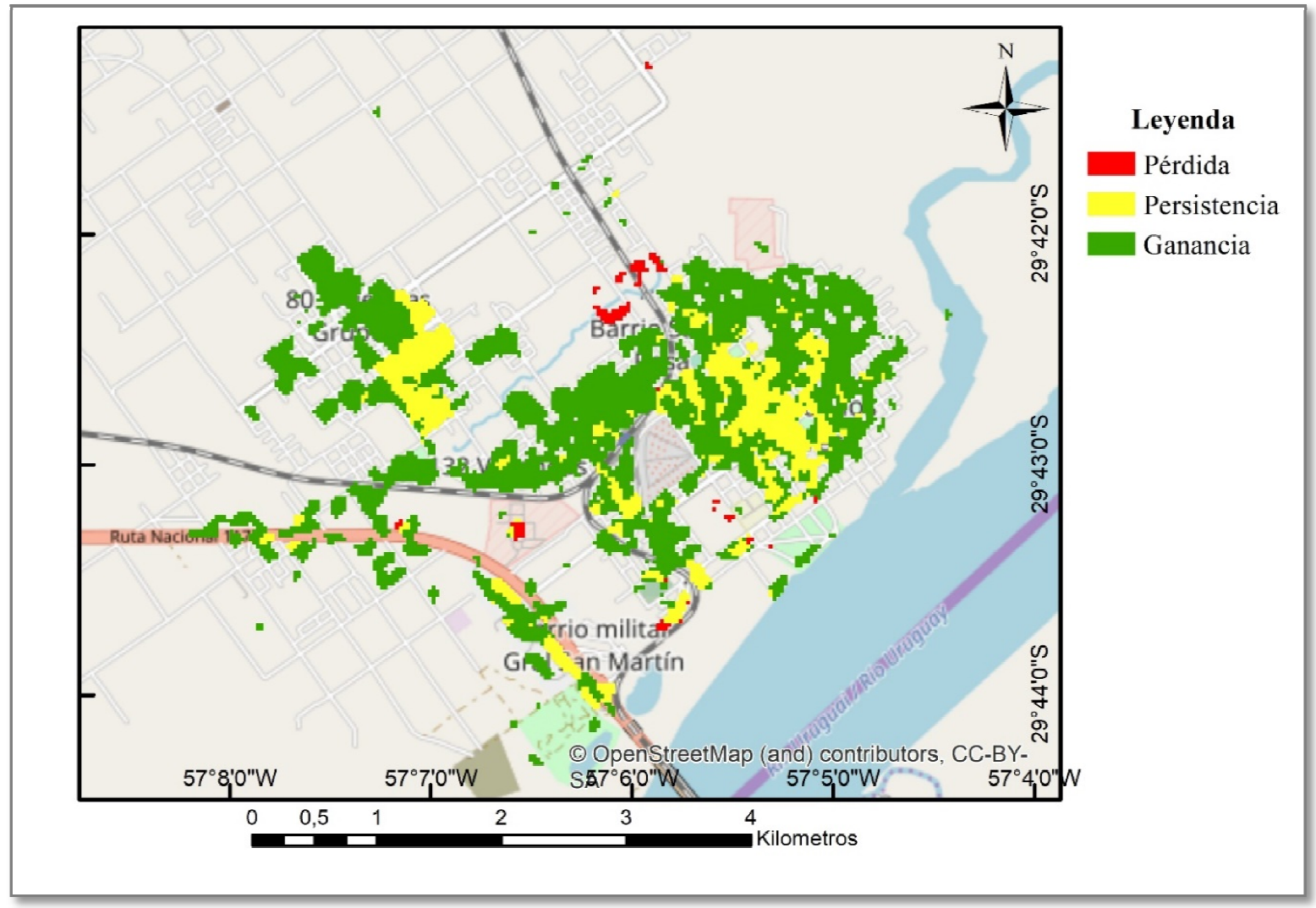

Fuente: Elaboración Propia

Sintetizando la categoría AUC registra un cambio total de aproximadamente 500hectáreas, que supera en un valor considerablea lo reflejado por el valor de cambio neto(420hectáreas), lo que significa que esta categoría tuvo intercambios con las restantes categorías analizadas. En este sentido a continuación se muestra la información estadística (tabla 5) y espacial (mapa 8) producto de ese intercambio.

Tabla 5: Transicionesentre AUC y las restantes categorías

\begin{tabular}{|c|c|c|c|}
\hline Leyenda & Has & Leyenda & Has \\
\hline INF a AUC & 307,26 & AUC a INF & 22,05 \\
\hline CCA a AUC & 13,32 & AUC a CCA & 2,25 \\
\hline AVCVU a AUC & 48,33 & AUC a AVCVU & 9,36 \\
\hline AP a AUC & 91,08 & AUC a AP & 6,12 \\
\hline & 459,99 & & 39,38 \\
\hline
\end{tabular}

Fuente: Elaboración Propia

Publicado en formato digital: Agrim. Prof. Laura Fabiana Gomez. CAMBIOS DE USOS DE SUELO EN PASO DE LOS LIBRES, CORRIENTES, ARGENTINA ENTRE 1990 Y 2016. Impacto del Proceso de Expansión Urbana. Revista Geográfica Digital. IGUNNE. Facultad de Humanidades. UNNE. Año 15. № 30. Julio - Diciembre 2018. ISSN 1668-5180 Resistencia, Chaco.

En: http://hum.unne.edu.ar/revistas/geoweb/default.htm 
Mapa 8: Espacialidad de las transiciones de las distintas categorías al AUC entre 1990 y 2016

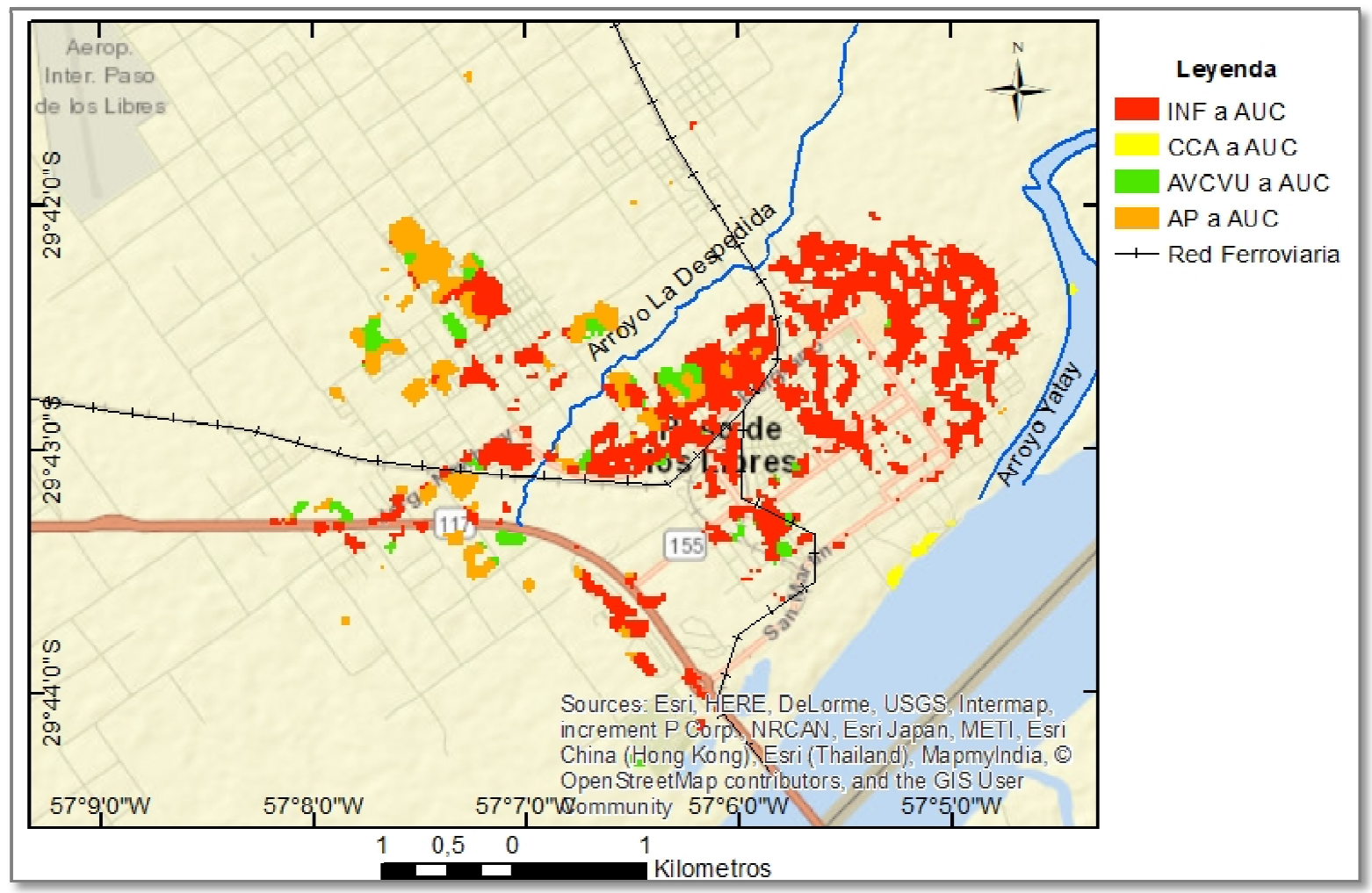

Fuente: Elaboración Propia

\section{CONSIDERACIONES FINALES}

Según datos del Banco Mundial, Argentina se encuentra entre los países con mayor porcentaje de población urbana $(91,75 \%$ al año 2017$)$. En particular, la provincia de corrientes ya contaba al año 2010 con un $82 \%$ de población urbana y la ciudad de Paso de los Libres superaba el $90 \%$ (INDEC, 2010). La preferencia de la población por las ciudades se manifiesta en todas las escalas y se evidencia en el aumento de la misma conforme avanzar los años y en el impacto que genera sobre los usos del suelo.

La ciudad de Paso de los Libres ha experimentado en el lapso de 26 años un crecimiento del suelo urbano muy superior al crecimiento de su población, configurándose como una ciudad de baja densidad poblacional, extendida de forma horizontal, con presencia de grandes espacios vacíos correspondientes a inmuebles de dominio del estado nacional o de dominio particular como así también superficies destinadas a barrios militares.

En otro orden de cosas,el análisis basado en imágenes satelitales en un estudio multitemporal, las métricas obtenidas y la cartografía derivada, permiten avanzar en la generación de información para la obtención de una mejor aproximación al conocimiento del comportamiento del proceso de expansión urbana y los cambios de usos del suelo, configurándose como un insumo para los actores involucrados en la planificación de la ciudad. 


\section{REFERENCIAS}

- Bellet, Carmen, 2000. "Ciudades intermedias. Urbanización y globalización” Conferencia realizada en el marco del Seminario: Red de ciudades intermedias para el valle del Cauca, Cali (Colombia)(12 de Octubre).

- Bellet, Carmen y Llop, Josep Maria, 2004. Miradas a otros espacios urbanos: las ciudades intermedias.Geo

Crítica

Scripta

Revista Electrónica

Universidad de Barcelona. 1SSN: 1138-9788.

Vol. VIII, núm. 165, 15 de mayo de 2004. Disponible en: http://www./ub.edu/geocrit/sn/sn165.htm

- Buzai, Gustavo, 2016. Mapas Sociales Urbanos. 1ra edición. Ciudad Autónoma de Buenos Aires. Lugar Editorial. Pp. 292

- Buzai, Gustavo, Baxendale, Claudia, Humacata, Luis y Prinicipi, Noelia (2016). Sistemas de Información Geográfica. Cartografía Temática y análisis espacial.1ra edición. Ciudad Autónoma de Buenos Aires. Lugar Editorial. Pp. 152

- Cardozo, O. y Da Silva, C, 2013. Aplicaciones Urbanas de los Sensores Remotos.Revista Geográfica Digital. IGUNNE. Facultad de Humanidades. UNNE. Año 10. № 20. Julio Diciembre 2013. ISSN 1668-5180 Resistencia, Chaco

- Hurtubia, Ricardo y Cox, Tomás, 2017. Expansión Urbana y Accesibilidad. Disponible en http://www.plataformaurbana.cl/archive/2017/05/29/expansion-urbana-y-accesibilidad/

- INDEC. 1991Censo Nacional de Población, Hogares y Viviendas.

- INDEC.2010 Censo Nacional de Población, Hogares y Viviendas. https://www.indec.gob.ar/nivel4 default.asp?id tema 1=2\&id tema 2=41\&id tema $3=135$ [fecha de consulta: 15/07/2017].

- INDEC,2018 Proyecciones y estimaciones. https://www.indec.gob.ar/nivel3 default.asp?id tema 1=2\&id tema $2=24$ [fecha deconsulta: 10/07/2018].

- López Trigal, Lorenzo (2010) Diccionario de términos sobre la ciudad y lo urbano. Madrid: Biblioteca Ariel, pp. 421

- López Trigal, L. (2015). Diccionario de Geografía aplicada y profesional. Terminología de análisis, planificación y gestión territorial. Universidad de León, pp. 676.

- López Vazquez, V. y Plata Rocha, W. 2009. Análisis de los cambios de cobertura de suelo derivados de la expansión urbana de la Zona Metropolitana de la Ciudad de México, 1990-2000. Investigaciones Geográficas, Boletín del Instituto de Geografía, UNAM, N 68, pp. 85-101.

- Mayor Farguell, X, 2007 Reflexiones sobre la ciudad: más allá de la ciudad difusa, más allá de la ciudad densa. En La ciudad de baja densidad Lógicas, gestión y contención, Franciso Indovina (Coord.) Colección Estudios. Serie Territorio 1, Barcelona, 265-276.

- Naciones Unidas. Departamentos de asuntos económicos y sociales. Consultado 22/10/2018 (https://www.un.org/development/desa/es/news/population/2018-world-urbanizationprospects.html)

- Olaya, Victor. 2014.Sistemas de información geográfica. Recuperado de: http://www. icog.es/TyT/files/Libro_SIG.pdf.

Publicado en formato digital: Agrim. Prof. Laura Fabiana Gomez. CAMBIOS DE USOS DE SUELO EN PASO DE LOS LIBRES, CORRIENTES, ARGENTINA ENTRE 1990 Y 2016. Impacto del Proceso de Expansión Urbana. Revista Geográfica Digital. IGUNNE. Facultad de Humanidades. UNNE. Año 15. № 30. Julio - Diciembre 2018. ISSN 1668-5180 Resistencia, Chaco.

En: http://hum.unne.edu.ar/revistas/geoweb/default.htm 
Revista Geográfica Digital. IGUNNE. Facultad de Humanidades. UNNE. Año 15. № 30. Julio - Diciembre 2018. ISSN 1668-5180 Resistencia, Chaco

- Plan estratégico de ordenamiento territorial del municipio de paso de los libres. 2013. Convenio CFI- UNNE. Convenio provincia de Corrientes - UNNE - Facultad de Arquitectura y Urbanismo -Instituto de Planeamiento Urbano y Regional -BAT.

- Pontius, Robert; Emily Shusasy Menzie Mceachern. 2004. Detecting important categorical land changes while accounting for persistence. Agriculture, Ecosystems and Environment, $\mathrm{N}^{\circ} 101,251-268$.

- Ramirez, Liliana y Pértile, Viviana. 2015. El proceso de urbanización del Chaco, expansión urbana, cambios de uso en ciudades intermedias de la Provincia del Chaco, Argentina. 6o Seminario de Políticas Urbanas, Gestión Territorial y Ambiental para el Desarrollo Local. Facultad de Arquitectura y Urbanismo de la UNNE y Ministerio de Educación de la Nación. Junio 2015

- Ramirez, L. y Pertile, V. (2017). Crecimiento poblacional, expansión urbana y cambio de usos de suelo en ciudades intermedias de la provincia del Chaco, Argentina. El caso de Juan José Castelli. Estudios Socioterritoriales № 21. Enero-junio 2017. Pp. 111-131.

- Tella, Guillermo y Potocko, Alejandra. 2018. Guía para generar suelo urbano en ciudades intermedias: Lineamientos y criterios para la de gestión del territorio. Disponible en:http://www.plataformaurbana.cl/archive/2018/03/19/guia-para-generar-suelo-urbano-enciudades-intermedias-lineamientos-y-criterios-para-la-de-gestion-del-territorio/.

- UIA, 1999. Ciudades intermedias y urbanización mundial. Disponible en:http://www.ceut.udl.cat/wp-content/uploads/5.BOOK1 .pdf

- UIA, 2016. Documento Marco de CGLU para ciudades intermedias. Planificación y Gestión del Desarrollo Urbano sostenible de las Ciudades Intermedias. Disponible en: https://www.uclg.org/sites/default/files/cglu documento marco ci 0.pdf

\section{NOTAS}

${ }^{1}$ El concepto ciudad intermedia no es de fácil definición ni acotación. En gran medida, éste depende del contexto territorial" (Ciudades Intermedias y Urbanización Mundial, 1999:23). Cuantitativamente, en Argentina, una Ciudad Intermedia es aquella que cuenta con una población de entre 50.000 y 1.000.000 de habitantes (Bellet et al., 2004)

${ }^{2}$ Documento Marco de CGLU para ciudades intermedias. Planificación y Gestión del Desarrollo Urbano sostenible de las Ciudades Intermedias.

${ }^{3}$ Asociada a la revolución de los transportes y de las relaciones sociales y económicas de la sociedad. Puede tratarse de una remodelación del espacio interno de la ciudad, aumentando la densidad poblacional al dedicar espacios antes destinados a industrias o servicios, a residencias 0 equipamientos colectivo; o de un proceso de edificación avanzando sobre el espacio periurbano, generando nuevas formas y tipologías de espacios urbanos, suburbanización de áreas periféricas y profundizando el cambio en los usos de suelo. (López Trigal, 2010)

${ }^{4}$ En la provincia de Corrientes, todo centro de población que cuente con más de quinientos (500) habitantes constituye un municipio con arreglo a las prescripciones de la Constitución Provincial sancionada el 12 de febrero de 1993. Los municipios se dividen en tres categorías: Ios municipios de primera categoría son aquellos que superan los quince mil (15.000) habitantes; los de segunda categoría, aquellos con menos de quince mil (15.000) y más de cinco mil (5.000) habitantes; y los de tercera categoría, aquellos con menos de cinco mil (5.000) y más de quinientos (500) habitantes.

${ }^{5}$ Ley Provincial N5960; y Dto. 143/11 art 39

${ }^{6}$ Información proveniente del registro gráfico catastral brindado por la Dirección General de Catastro y Cartografía de la Provincia de Corrientes. Fecha de consulta: 09/03/2018 
${ }^{7}$ Tomando en cuenta la información provista por elMDE-Ar desarrollado por el Instituto Geográfico Nacional (IGN) a partir de información proveniente de la misión SRTM (Shuttle Radar Topography Mission) (http://ign.gob.ar/NuestrasActividades/Geodesia/ModeloDigitalElevaciones/Introduccion).

8 "Las áreas cubiertas por estos polígonos reflejan las zonas de influencia de cada entidad, influencia que se considera la ejerce hasta una distancia dada. Pueden verse también en de forma inversa, como una influencia recibida, de tal modo que todos los elementos dentro de la zona de influencia afectan a la entidad que la genera". (Olaya, V., 2014: 846).

${ }^{9}$ Ley Orgánica de las Municipalidades / Ley № 4752

${ }^{10}$ Ley Orgánica de las Municipalidades / Ley № 4752

${ }^{11}$ Cantidad de Habitantes para el año 1991. Año de realización del Censo Nacional de Hogares y Viviendas.

${ }^{12} \mathrm{~A}$ partir de los 7,5 metros se considera estado de alerta y desde los 8,5 metros estado de evacuación de la población (PNA).

${ }^{13}$ Información obtenida de la Base de Datos Hidrológica Integrada. Subsecretaría de Recursos Hídricos. Disponible en: http://bdhi.hidricosargentina.gob.ar/MuestraDatos.aspx?Estacion=13802 (Fecha de Consulta: 22/10/2018) 